\title{
MEMBANGUN TATA KELOLA GARAM BERDAYA SAING
}

\author{
Yonvitner $^{1 *}$, Surya Gentha Akmal ${ }^{2}$ \\ ${ }^{1}$ Pusat Studi Bencana (PSB), Lembaga Penelitian dan Pengabdian kepada Masyarakat, Institut Pertanian \\ Bogor (IPB) \\ *Email: yonvitr@yahoo.com
}

\section{RINGKASAN}

Negeri bahari impor garam, sungguh sebuah ironi ketika duapertiga wilayah kita adalah laut. Kenapa hal ini terjadi, jawabnya sederhana, yaitu karena tidak adanya keberpihakan kepada petambak garam atau nelayan skala kecil. Untuk itu perlu sebuah telaah yang substansial untuk penyelesaian persoalan garam nasional ini. Setidaknya ada 5 langkah intervensi untuk menyelesaikan persoalan garam nasional dengan 3 dimensi tata kelola untuk menjadikan petambak garam lebih berdaya. Hanya dengan merubah konsep tata kelola ini, kita akan mampu mendorong sistem usaha tambak garam dan petambak yang berdaya saing.

Kata Kunci: Berdaya Saing, Dimensi Usaha, Garam, Intervensi, dan Tata Kelola.

\section{PERNYATAAN KUNCI}

- Kemandirian garam adalah wujud dari kedaulatan petambak dalam bangsa bahari.

- Swasembada garam adalah bentuk wujud dari keberpihakan terhadap petambak garam sektor perikanan dan kelautan.

- Menjauhkan impor dan memandirikan petambak adalah sikap pengayoman dari kemampuan tata kelola yang berpihak pada keunggulan potensi bangsa.

- Tata kelola yang berpihak pada petambak garam adalah adalah wujud dari sikap pembangunan yang kompetitif dan berdaya saing.

- Negara akan maju apabila mampu memberdayakan rakyatnya untuk menjadi penyedia kebutuhanya sendiri tanpa menggantungkan hidupnya pada bangsa lain apalagi impor.

- Sikap impor garam adalah bentuk dari distorsi kebijakan dan kerjasama antara lembaga yang tidak solid serta tidak membumi.

\section{REKOMENDSI KEBIJAKAN}

Persoalan impor garam harus dihentikan dengan lebih awal menyiapkan sistem neraca perdagangan garam. Belum adanya neraca garam menjadi celah bagi maraknya import dan dapat memperburuk kondisi pertambakan dan petambak garam nasional. Setidaknya ada 5 intervensi penting yang harus diadaptasikan dalam memandirikan petambak garam. Kelima intervensi tersebut adalah 1) revitalisasi lahan tambak potensi dan produktif, 2) 
menfungsikan sistem usaha industri garam rakyat, 3) adaptasi teknologi Io'T dan 4.0 dalam mengelola membangun neraca garam dan data garam, 4) intervensi pasar dari produk garam, 5) intervensi kebijakan terutama dalam sinkronisasi PP Nomor 9 Tahun 2018 tentang Impor Garam sebagai turunan UU Nomor 7 Tahun 2017 tentang Perlindungan Nelayan.

\section{PENDAHULUAN}

Sikap pemerintah dengan menerbitkan PP Nomor 9 Tahun 2018 tentang Tata Cara Pengendalian Impor Komoditas Perikanan dan Komoditas Pergaraman sebagai bahan baku dan bahan penolong industri adalah sebuah disrupsi pada sistem usaha pertambakan nelayan. Sektor perikanan dan kelautan seperti tidak berdaya menghadapi penerbitan PP ini, karena, 1) apakah memang Indonesia kekurangan garam dan harus impor garam sebesar 2,3 juta ton; 2) apakah kinerja organisasi pemerintah selalu mengutamakan mekanisme pasar dari usaha masyarakat, sehingga harus segera diluruskan; 3) apakah sudah ada neraca garam nasional yang menjadi patokan bersama dan bersifat inklusif; serta 4) keterlibatan menteri teknis dalam memberikan pertimbangan terhadap waktu, volume, distribusi dan pengawasan juga harus diintegrasikan, agar kesan penetapan PP sebagai konsideran bersama.
Terjadinya pertentangan yang kemudian mengarah pada polarisasi sikap, kemudian menyeruak ketika PP No 9 ini keluar. Keadaan ini tentunya sangat bertentangan dengan semangat UU Nomor 7 Tahun 2016 tentang Perlindungan dan Pemberdayaan Nelayan, Pembudi Daya Ikan, dan Petambak Garam. Keberadaan UU Nomor 7 sebetulnya cukup waktu bagi pemerintah dan kementrian teknis untuk memberdayakan nelayan, pembudidaya ikan dan petambak garam. Seharusnya efisiensi belanja anggaran kementrian kelautan perikanan 2017 dapat dijadikan stimulus dalam percepatan implementasi UU No 27 tahun 2016 tersebut. Waktu dua tahun jika digarap dengan serius serta visi yang tajam dalam pengarusutamaan ekonomi perikanan dan kelautan akan mempercepat pembangunan negara maritim Indonesia melalui usaha garam ini. Dari kondisi tersebut kita mesti berpikir ada hal yang salah dalam mekanisme perdagangan garam nasional dan kemandirian sektor perikanan dan kelautan.

Benarkah kita kekurangan garam? Sebegitu tidak mampukah kita menyiapkan garam untuk kebutuhan masyarakat dan industri kita? Berbagai pertanyaan menyeruak ke permukaan saat pemerintah merancang impor garam dengan kuota 2,7 juta ton tahun 2018 menjadi bagian dari analisis yang penulis angkat dalam tulisan ini. 


\section{METODOLOGI}

Metode yang dipilih dalam kajian dan telaah ini adalah kajian logic thingking dimana setiap sebab selalu ada akibat. Sehingga telaah lebih cenderung menggunakan analisis kerangka logis ini untuk memastikan bahwa ada interaksi dari kebijakan impor garam, ada dampak dari kebijakan impor garam, dan ada solusi yang ditawarkan ketika keluar dari persoalan impor garam.

Kebijakan yang mendukung untuk proses pembangunan masyarakat yang berkeadilan perlu diwujudkan dalam sebuah desain tata kelola yang baik. Mekanisme yang disiapkan seperti terlihat dalam bagan alur berikut pada Gambar 1.

\section{SITUASI TERKINI}

Keyakinan kita terhadap kemampuan bangsa dalam menyiapkan garam nasional bahkan untuk kebutuhan ekspor sangat tinggi karena wilayah kita yang luas. Setidaknya tercatat 48 kabupaten/kota yang tercatat sebagai sentra industri garam. Semua kawasan tersebut ada di kawasan pesisir dan laut. Dari 48 kabupaten/kota tersebut baru 19 daerah yang memiliki gudang garam dan penampungan garam.

Sebaran wilayah usaha tambak garam nasional disajikan dalam Gambar 2.

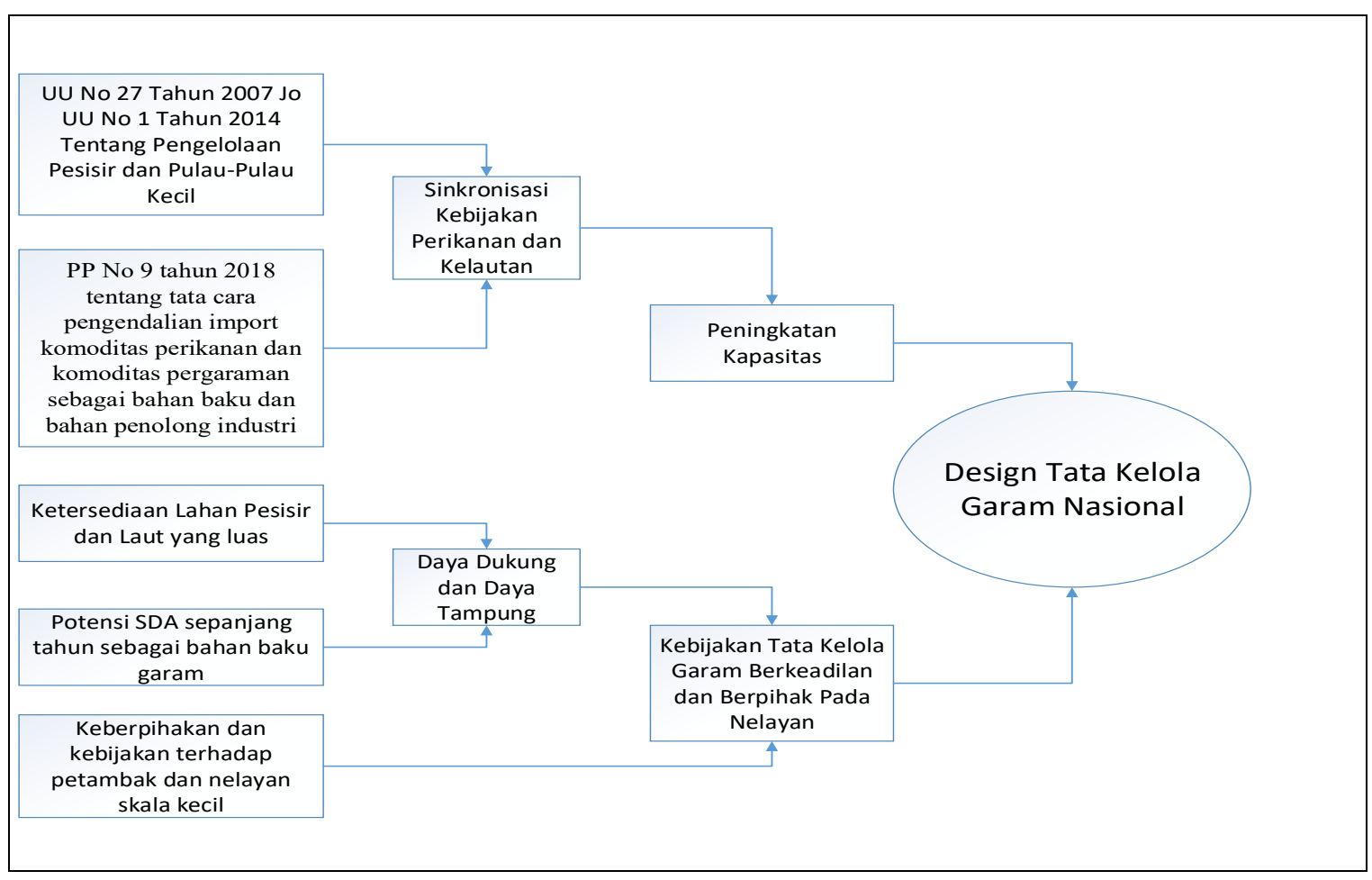

Gambar 1. Kerangka logik design tata kelola garam yang berkeadilan dan berdaya saing 


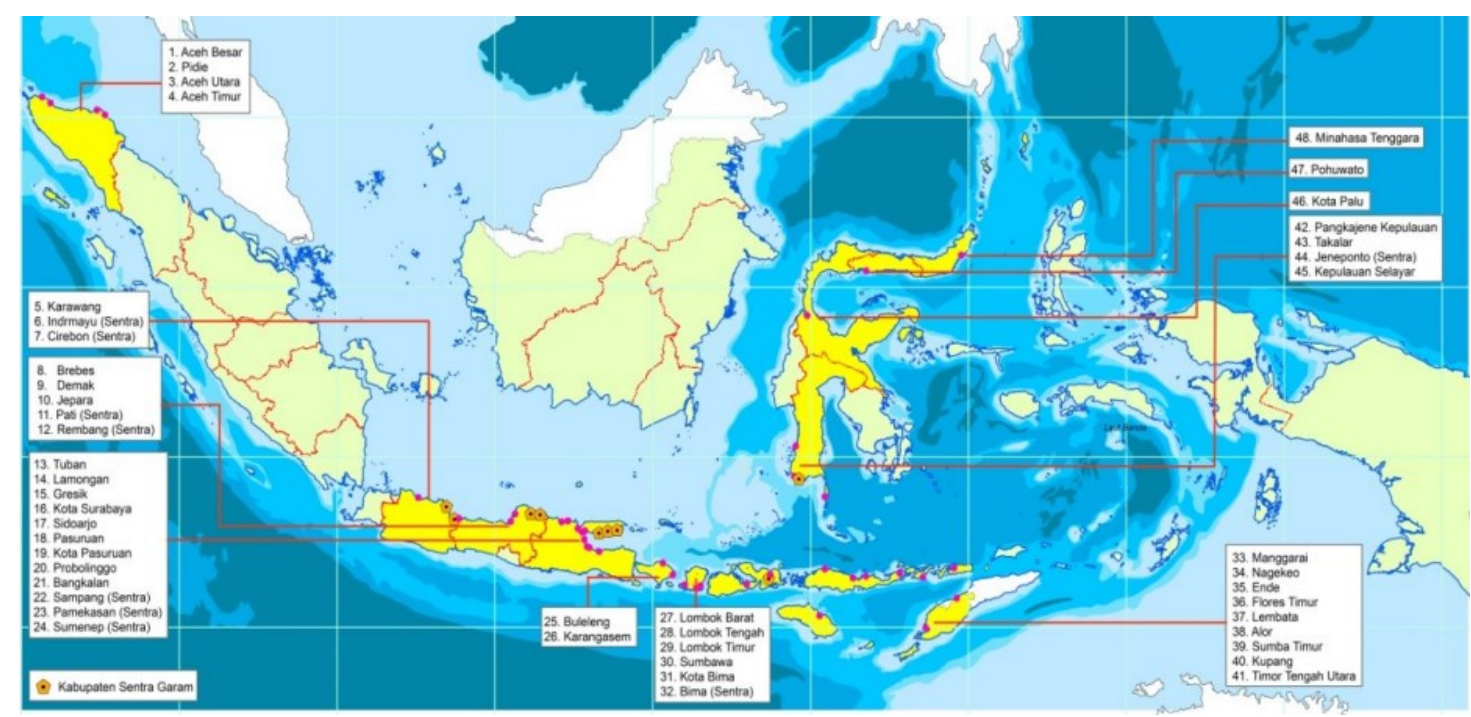

Gambar 2. Sebaran daerah produksi tambak garam nasional (sumber: KKP, 2019)

Berdasarkan catatan data produksi garam nasional, sejak tahun 2012 sampai 2019 rata rata kebutuhan garam nasional adalah 3,5 juta ton dan baru mampu dipenuhi sebanyak 1,5 juta ton. Artinya secara rata-rata terdapat selisih kekurangan sekitar 2,0 juta ton, walaupun kadang terjadi selisih yang lebih besar karena garam gagal produksi. Namun dengan modifikasi media produksi dengan geomembran (Arwiyah $e t$ al, 2015) dapat meningkatkan produktivitas. Perbandingan antara produksi dan kebutuhan garam nasional yang diolah dari data KKP (2019) seperti disajikan pada Gambar 3.

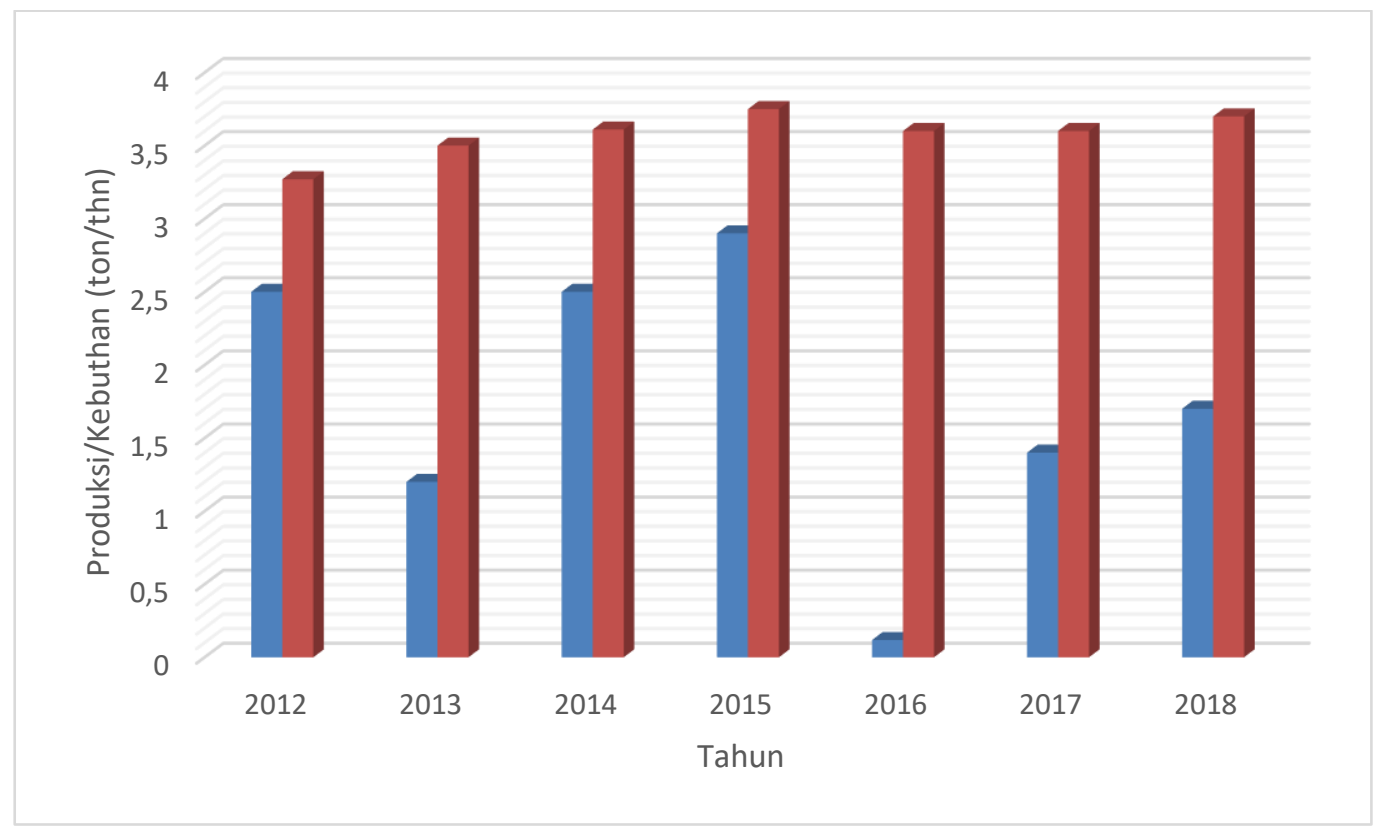

Gambar 3. Perbandingan Produksi dan Kebutuhan Garam Nasional (ton/thn) 
Walaupun memang terjadi kekurangan produksi garam nasional saat musim hujan (Kurniawan, 2012), namun seringkali pemerintah tetap menetapkan impor dalam jumlah rasio yang lebih besar. Akibatnya ketika impor masuk, garam rakyat menjadi tidak terserap. Kondisi inilah kemudian yang menyebabkan nelayan mengalami kerugian dari produksi garam. Padahal seharusnya kekurangan garam yang kemudian impor, manfaatnya dapat diambil petambak garam. Dengan demikian maka garam akan terus diusahakan oleh petambak garam karena kebutuhan tetap meminta suplai yang memadai. Dengan kondisi produksi saat ini, dan tidak ada perubahan permintaan, sesungguhnya kehidupan petambak garam tergolong cukup dan tidak miskin (Wijaya et al, 2013) namun bisa berubah mendadak menjadi miskin karena produksi garam tidak terjual. Sesungguhnya petambak garam tergolong sebagai kelompok masyarakat yang rentan mengalami perubahan.

\section{ALTERNATIF SOLUSI}

Ketika impor garam tidak menjadi solusi, maka kita harus dapat menyiapkan skema industrialisasi tambak garam nasional. Ada 5 intervensi yang perlu dipersiapkan untuk mencapai skema swasembada garam seperti terlihat pada arah alur proses intervensi berikut (Gambar 4).

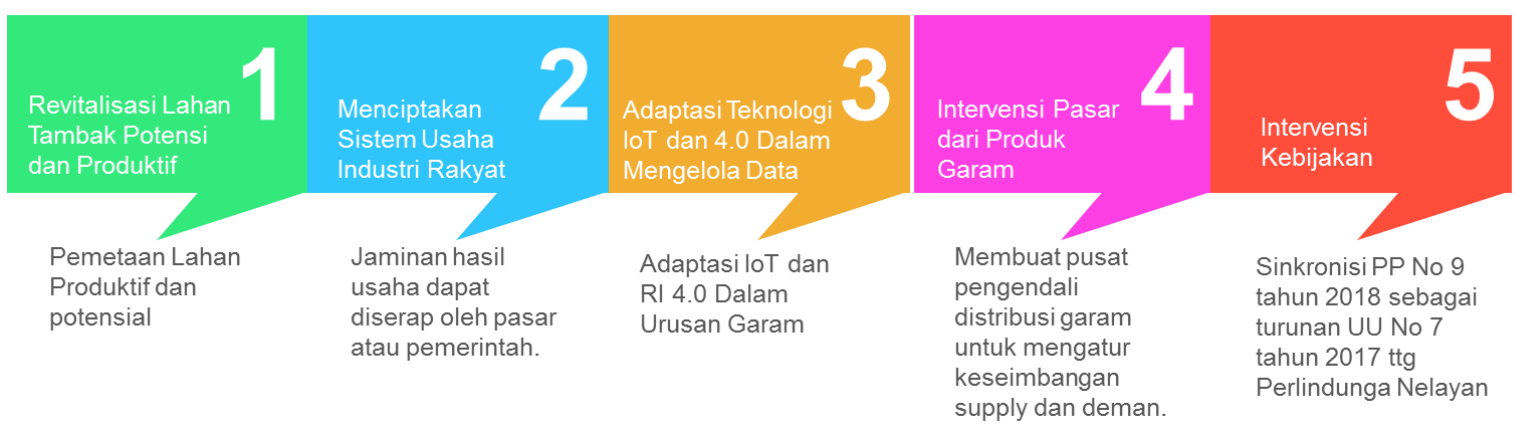

Gambar 4. Intervensi usaha tambak garam nasional mewujudkan kemandirian

Sebagai basis dasar dalam intervensi ini, maka orientasi spasial menjadi penting dan prioritas dilakukan. Kemudian baru dilanjutkan dengan re-desain sistem usaha, adaptasi teknologi 4.0 intervensi pasar dan kebijakan. Dengan menyiapkan semua ini, maka sistem usaha tambak garam dapat diperjuangkan. Membangun industri garam, dan menghentikan impor merupakan dua mashab ekonomi yang dikembangkan yaitu mashab ekonomi kapitalisme dan mashab ekonomi kerayatan. Maka untuk itu setting industri garam haruslah 1) dengan pembinaan berkelanjutan, 2) berbasis 
inovasi, 3) kompetitif kemampuan menghasilkan produk garam yang dibutuhkan pasar serta 4) berbasis sistem informasi dan teknologi industri 4.0.

\section{TATA KELOLA}

Untuk mewujudkan sistem usaha tambak garam yang berbasis masyarakat, berkeadilan, sehat, dan berkualitas, maka konsep pengembangan garam harus berbasis desa. Untuk itu perlu dilakukan sinergi antara pembudidaya, pembeli (buyer) serta KUD atau depot dan gudang garam sebagai distributor penyalur, sehingga pasar garam tidak lagi monopolisitk dan dikuasai pemilik modal (Rochwulaningsih, 2013) saja. Hubungan dari ketiga poin tersebut dikenal sebagai tata kelola garam untuk keadilan masyarakat yang berdaya saing pada Gambar 4.

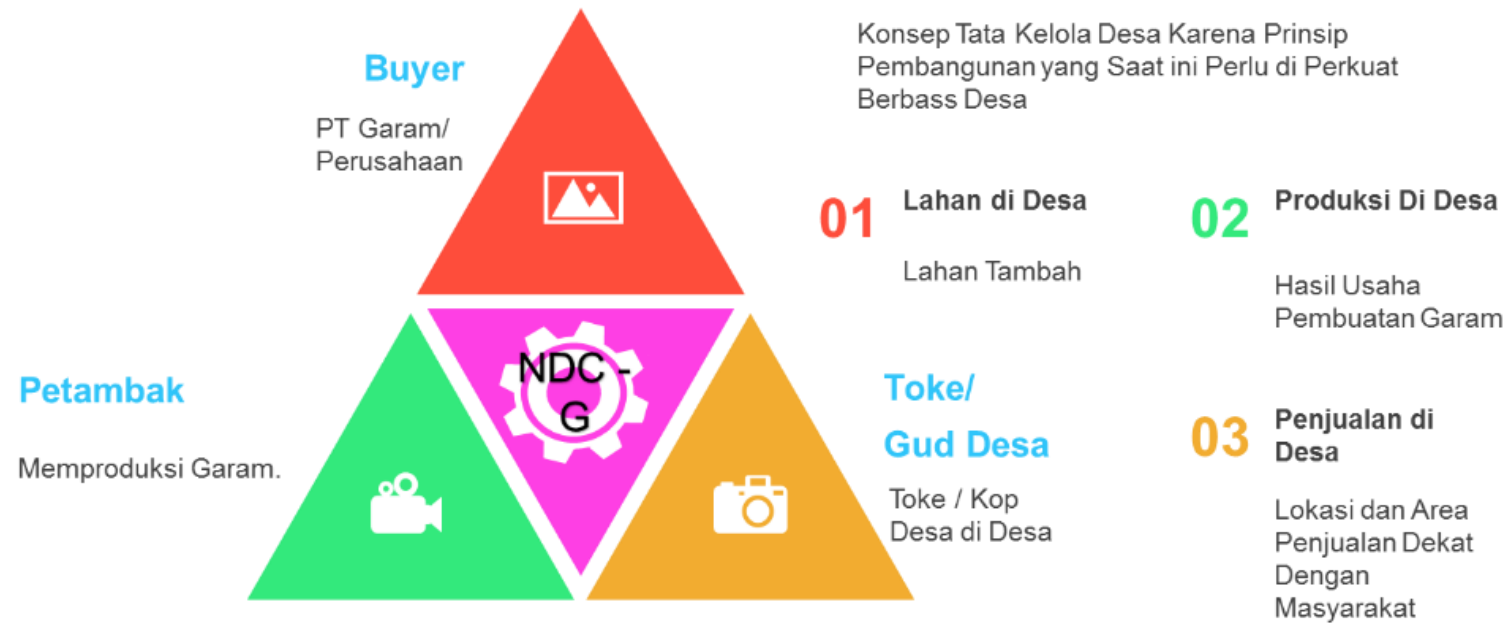

Gambar 5. Tata kelola garam untuk keadilan berdaya saing

Dengan konsep tata kelola garam berbasis desa maka setidaknya 1) kita telah memberikan kesempatan peluang kerja lebih besar pada masyarakat desa, 2) akan lebih mudah terpantau terkontrol secara spasial dengan keberadaan RI 4.0, 3) dapat menjadi indikator kinerja desa pesisir agar mampu menggerakan aktivitas masyarakat, serta 4) dapat mewujudkan masyarakat yang berkeadilan atas persamaan akses terhadap produk, jasa dan sumberdaya alam pesisir dan laut dan tidak lagi termarjinalkan (Rochwulaningsih, 2007).

Jangan lagi mempersoalkan kualitas garam yang dihasilkan petani garam sebagai delik untuk impor, karena dengan teknik kritalisasi kemurnian garam produksi menjadi garam konsumsi meningkat 10,52\% (Maulana et al, 2017) atau dengan penambahan $\mathrm{Na}_{2} \mathrm{CO}_{3}, \mathrm{NaOH}$ dan PAC selama kristalisasi 1,5 jam (Agustina et al, 2013). Jika lama waktu produksi menjadi 
persoalan maka kita bisa memiliki teknologi yang tepat semisal penambahan plat pemanas (Maulana et al, 2017) sehingga bisa dipenuhi dalam waktu cepat.

\section{REFERENSI}

Agustina, L.R., Citra, M.T., Danny, S. 2001. Rekristalisasi Garam Rakyat dari Daerah Demak untuk Mencapai SNI Garam Industri. Jurnal Teknologi Kimia dan Industri, 2(4), 217-225.

Arwiyah, A., Zainuri, M., Efendy, M. 2015. Studi kandungan $\mathrm{NaCl}$ di dalam air baku dan garam yang dihasilkan serta produktivitas lahan garam menggunakan media meja garam yang berbeda. Jurnal Kelautan: Indonesian Journal of Marine Science and Technology, 8(1), 1-9.

KKP. 2019. Data Produksi Garam Nasional. Ditjen PRL KKP.

Kurniawan, T., Azizi, A. 2012. Dampak perubahan iklim terhadap petani tambak garam di Kabupaten Sampang dan Sumenep. Jurnal Masyarakat dan Budaya, 14(3), 499518.

Maulana, K.D., Jamil, M.M.M., Putra, P.E.M., Rahmawati, R., Rohmawati,
B. 2017. Peningkatan Kualitas Garam Bledug Kuwu Melalui Proses Rekristalisasi dengan Pengikat Pengotor $\mathrm{CaO}, \mathrm{Ba}(\mathrm{OH})$ 2, dan (NH4) 2CO3. Journal of Creativity Student, 2(1), 42-46.

Maulana, R.P., Mulyanef, M.M., Kaidir, K.K. 2017. Performansi Termal Destilasi Surya untuk MengolahAir Laut Menjadi Garam dan Air Tawar dengan Penambahan Kolektor Plat Datar. Fakultas Teknologi Industri. Universitas Bung Hatta.

Rochwulaningsih, Y. 2007. Petani Garam dalam Jeratan Kapitalisme, Analisis Kasus Petani Garam di Rembang Jawa Tengah. Jurnal Masyarakat, Kebudayaan dan Politik Tahun XX, (3).

Rochwulaningsih, Y. 2013. Tata Niaga Garam Rakyat dalam Kajian Struktural. Citra Lekha, 17(1), 59-66.

Wijaya, R.A., Firdaus,M., Ramadhan, A. 2013. Tingkat kemiskinan dan ketahanan pangan rumah tangga petambak garam berdasarkan status penguasaan lahan. Jurnal Sosial Ekonomi Kelautan dan Perikanan, 8(1), 61-74. 